Published in final edited form as:

Am J Geriatr Psychiatry. 2014 July ; 22(7): 670-681. doi:10.1016/j.jagp.2013.02.015.

\title{
Mild Cognitive Impairment, Incidence, Progression, and Reversion: Findings from a Community-based Cohort of Elderly African Americans
}

\author{
Sujuan Gao, Ph.D. ${ }^{1}$, Frederick W. Unverzagt, Ph.D. ${ }^{2}$, Kathleen S. Hall, Ph.D. ${ }^{2}$, Kathleen A. \\ Lane, M.S. ${ }^{1}$, Jill R. Murrell, Ph.D. ${ }^{3}$, Ann M. Hake, M.D. ${ }^{4}$, Valerie Smith-Gamble, M.D. ${ }^{2,5}$, and \\ Hugh C. Hendrie, M.B., Ch.B., D.Sc. ${ }^{2,6,7}$ \\ ${ }^{1}$ Department of Biostatistics, Indiana University School of Medicine, Indianapolis, Indiana \\ ${ }^{2}$ Department of Psychiatry, Indiana University School of Medicine, Indianapolis, Indiana \\ ${ }^{3}$ Department of Pathology and Laboratory Medicine, Indiana University School of Medicine, \\ Indianapolis, Indiana \\ ${ }^{4}$ Department of Neurology, Indiana University School of Medicine, Indianapolis, Indiana \\ ${ }^{5}$ Richard L. Roudebush Veterans Administration Medical Center, Indianapolis, IN, USA \\ ${ }^{6}$ Indiana University Center for Aging Research, Indianapolis, IN \\ ${ }^{7}$ Regenstrief Institute, Inc., Indianapolis, IN \\ ${ }^{5}$ Department of Neurology, Indians University Indianapolis, IN
}

\begin{abstract}
Objective-To examine the long-term outcomes of community-based elderly African Americans by following their transitions from normal cognition to mild cognitive impairment (MCI), and to dementia.
\end{abstract}

\footnotetext{
(C) 2013 American College of Cardiology Foundation. Published by Elsevier Inc. All rights reserved.

Address correspondence to: Sujuan Gao, Ph.D., Department of Biostatistics, Indiana University School of Medicine, 410 West $10^{\text {th }}$ Street, Suite 3000, Indianapolis, IN 46202-2872, Phone: U.S. (317) 274-0820, Fax: (317)274-2678, sgao@ iupui.edu. No disclosures to report.

Statistical analyses were completed by Sujuan Gao and Kathleen A. Lane from the Department of Biostatistics, Indiana University School of Medicine.

Disclosure: The authors report no conflicts of interest.

Author Contributions:

Drs. Gao, Unverzagt, Hall, Murrell, Hendrie - Study concept and design

Drs. Unverzagt, Hall, Hake, Smith-Gamble, Hendrie - acquisition of data

Dr. Gao, Ms. Lane, and Dr. Hendrie - analysis and interpretation

Drs. Gao, Unverzagt, Hall, Murrell, Hendrie - critical revision of the manuscript for important intellectual content

Drs. Hall, Hendrie - study supervision

Publisher's Disclaimer: This is a PDF file of an unedited manuscript that has been accepted for publication. As a service to our customers we are providing this early version of the manuscript. The manuscript will undergo copyediting, typesetting, and review of the resulting proof before it is published in its final citable form. Please note that during the production process errorsmaybe discovered which could affect the content, and all legal disclaimers that apply to the journal pertain.
} 
Methods-Participants were from the community-based Indianapolis Dementia Project. A total of 4104 African Americans were enrolled in 1992 or 2001 and followed until 2009 with regularly scheduled evaluation of cognitive assessment. A two-stage sampling was used at each evaluation to select individuals for extensive clinical assessment following the results of stage one cognitive testing. Age and gender specific incidence, progression and reversion rates for MCI were derived using the person-year method in a dynamic cohort and predicted probabilities from weighted multinomial logistic models of transitional probabilities among normal cognition, MCI and dementia.

Results-Annual overall incidence rate for MCI is 5.6\% (95\% CI: 4.6-6.6\%). Annual progression rate from $\mathrm{MCI}$ to dementia is $5.9 \%$ (95\% CI: 5.3-6.5\%) and annual reversion rate from MCI to normal is $18.6 \%$ (95\% CI: $16.7-20.4 \%$ ). Both MCI incidence rates and MCI to dementia progression rates increase with age, while reversion rates from MCI to normal decrease with age.

Conclusion-MCI progression to dementia is much more frequent in the older age groups than in the younger participants where reversion to normal cognition is more common. Future research is needed to determine factors related to the heterogeneous outcomes in MCI individuals.

\section{Keywords}

mild cognitive impairment; dementia; African Americans

\section{Introduction}

Dementia including Alzheimer's disease (AD) affects millions of elderly Americans and is emerging as a major public health problem. In an effort to identify individuals at higher risk for dementia, the intermediate stage between normal cognition and dementia has been characterized as mild cognitive impairment (MCI). ${ }^{1}$ Individuals in the MCI group were shown to progress to dementia at a higher rate than those with normal cognition suggesting that some MCI individuals may be at the early stage of dementia. However, epidemiological studies have also found that a substantial proportion of individuals with MCI revert to normal cognition indicating a highly heterogeneous nature of the MCI group. ${ }^{2-7}$ Information on the epidemiology of individuals with MCI including incidence, progression and reversion can help identify individuals at risk for dementia and lead to potential preventive measures in delaying conversion to dementia.

Previous studies on MCI have focused on separate cohorts of cognitive normal individuals at baseline for estimating incidence and cohorts of individuals with MCI at baseline for dementia progression. These studies have reported annual MCI incidence rates ranging from $0.85 \%$ to $12.2 \%{ }^{3-5,7-19}$ and annual progression rates to dementia ranging from $0.9 \%$ to $15.3 \% .{ }^{20}$ Since MCI is known to be a transient state between cognitive normal and dementia, it is essential to examine the incidence and progression of MCI simultaneously in population-based cohorts to appropriately account for transitions between normal cognition and MCI during follow-up. Few studies, if any, have examined the long-term outcomes of community-based elderly individuals by following their transitions from normal cognition to MCI and dementia. Various studies have indicated that African Americans were more likely 
than whites to have $\mathrm{AD}$ and other dementia. ${ }^{21}$ African Americans are also known to have higher prevalence of hypertension and diabetes than other ethnic groups, leading to potentially higher rates of MCI or MCI conversion rates. ${ }^{22-23}$ However, there has been little research on the natural history of MCI in African Americans. In this study, we report the incidence, progression and reversion rates of $\mathrm{MCI}$ in an elderly African American cohort from the Indianapolis Dementia Project.

\section{Methods}

\section{Study Participants}

Participants were from the Indianapolis cohort of the Indianapolis-Ibadan Dementia Project, a longitudinal study examining risk factors for dementia. Recruitment to the study was conducted at two time points. In the first recruitment in 1992, a cohort of African Americans age 65 or older living in Indianapolis were enrolled in the study. The geographic target area used in the study consisted of 29 contiguous census tracts in which African Americans represented $80 \%$ of the population in the 1990 U.S. census. Interviewers went door-to-door to randomly sampled addresses to invite African Americans age 65 years and over to participate. In 1992, 2,212 individuals were enrolled while 249 (9.6\%) refused, and 121 $(4.7 \%)$ were too sick to participate.

In 2001, the project enrolled additional community-dwelling subjects randomly selected from Medicare records, who were self- identified as African-Americans, and were at least 70 years of age. The age cut-off for the 2001 cohort was chosen in order to maintain comparability with the 1992 cohort since the youngest participants in the 1992 cohort had since turned 70 . Out of 7,583 eligible individuals, interviewers were able to contact 4,433 by telephone or home visit. Of those contacted, 1,892 (43\%) were enrolled, 2,020 (46\%) refused, $369(8 \%)$ were too ill, $100(2 \%)$ were deceased, $54(1 \%)$ had moved to a nursing home, and $14(0.3 \%)$ were not African American. The two cohorts were similar in basic demographics. Mean age during the 2001 evaluation was 77.4 ( $\mathrm{SD}=6.0$ ) for the 1992 cohort and $76.8(\mathrm{SD}=5.6)$ for the 2001 cohort. The two cohorts also have similar gender distributions (65.3\% female in the 1992 cohort and $65.0 \%$ in the 2001 cohort). ${ }^{24}$ All participants agreed to undergo regular follow-up cognitive assessment and clinical evaluations. The study was approved by the Indiana University-Purdue University of Indianapolis Institutional Review Board. All subjects enrolled provided informed consent. Details on the assembling of the original cohort and the enrichment cohort were described elsewhere. ${ }^{24-25}$

\section{Study Design}

The Indianapolis-Ibadan Dementia Project is a prospective community based study with a baseline evaluation followed by regular evaluations scheduled two to three years apart. Participants in the 1992 cohort were evaluated for up to 7 times, at 1992, 1995, 1998, 2001, 2004, 2007 and 2009. Participants in the 2001 cohort were evaluated for up to 4 times, at 2001, 2004, 2007 and 2009. 
A two-stage design was used at each evaluation with in-home cognitive and functional evaluations for all participants followed by a full diagnostic workup of selected participants based on the performance of stage one cognitive tests. After each stage one evaluation, study participants were divided into three performance groups (good, intermediate and poor) based on their cognitive and functional scores obtained during the in-home assessment and changes in scores from previous evaluations. ${ }^{26}$ Percentages sampled from each performance category were chosen to ensure that participants with the highest probability of dementia would be clinically assessed. All participants in the poor performance group were invited to be clinically assessed. Participants were randomly sampled from the intermediate performance group until 50\% had clinical assessments and from the good performance group until 5\% had clinical assessments.

Each clinically assessed participant received a diagnosis of "normal", MCI, or dementia, with further subtypes for those diagnosed with dementia (see section on Clinical Evaluation below). All individuals diagnosed as demented reached their endpoint in the study and were no longer followed. Participants who were diagnosed as MCI in a previous wave proceeded directly to the clinical assessment stage regardless of their first stage scores.

\section{Cognitive Instruments}

The Community Screening Interview for Dementia (CSID) was used during the first stage in-home assessment with a cognitive assessment of the study participant and an interview with a close relative evaluating the daily functioning of the participant. The CSID was developed by our group specifically for use in comparative epidemiological studies of dementia in culturally disparate populations. ${ }^{27-28}$ The cognitive assessment in CSID evaluates multiple cognitive domains (language, attention and calculation, memory, orientation, praxis, and comprehension and motor response) and details of its content and development are described elsewhere. ${ }^{12-14}$

\section{Clinical Evaluation}

Clinical evaluations included (1) a neuropsychological battery adapted from the Consortium to Establish a Registry of Alzheimer's Disease (CERAD); ${ }^{29}$ (2) a standardized neurologic and physical exam, and functional status review (The Clinician Home-based Interview to assess Function CHIF); ${ }^{30}$ and (3) a structured interview with a close relative adapted from the Cambridge Examination for Mental Disorders of the Elderly informant interview (CAMDEX) ${ }^{31-32}$ Following the second stage of evaluation, participants were diagnosed as having normal cognitive function, dementia, or MCI. Diagnosis was made in a consensus diagnostic conference of clinicians reviewing the CERAD neuropsychological test battery, the physician's assessment, the informant interview, and available medical records. Dementia was diagnosed with both the Diagnostic and Statistical Manual of Mental Disorders, Revised Third Edition (DSM-III-R $)^{33}$ and International Classification of Diseases, 10th Revision (ICD-10) ${ }^{34}$ criteria. AD was diagnosed using criteria proposed by NINCDS/ADRDA. ${ }^{35}$ Criteria for MCI were as follows: informant-reported decline in cognition, clinician's detected impairment in cognition during the assessment, or cognitive test scores 1.5 SD below the mean of the normative reference sample and normal instrumental and basic activities of daily living (based on the informant interview). ${ }^{7}, 17,36-37$ 


\section{Other Information}

Demographic information including age, sex and education were available on all study participants. Information was also collected on alcohol and smoking history on whether the participant ever consumed alcohol or smoked regularly. In addition, medical conditions that may affect cognitive function were collected at each of the evaluation times. In particular, medical history of coronary heart disease (CHD), cancer, diabetes, heart attack, hypertension, Parkinson's disease, stroke and depression was collected from self or informant reports as affirmative answers to whether the participants had ever been diagnosed or treated for these diseases.

\section{Statistical Analyses}

Comparisons of baseline demographic characteristics and medical history among participants with incident dementia, those with $\mathrm{MCI}$ at any given time during the study and participants who were not diagnosed as demented or MCI were conducted using Chi-square tests for categorical variables and analysis of variance for continuous variables for the 1992 cohort and the 2001 cohort separately.

To account for the two-stage sampling design, weighted multinomial logistic regression models were used to model the transitional probabilities of participants diagnosed with normal cognition at a particular evaluation transitioning into MCI, dementia or stay as cognitively normal at the next follow-up. Weighted multinomial logistic regression models were also used to model the transitional probabilities of participants diagnosed as $\mathrm{MCI}$ at a particular evaluation reverting to normal cognition, stay as MCI, or progress to dementia. The multinomial logistic models used transitional states as the outcome variables with age, gender, years of education and performance groups from stage one cognitive assessment as independent variables. The weights were the reciprocals of sampling probabilities for clinical assessment at each evaluation.

The person-years method was used to estimate age and gender specific annual transitional probabilities from normal cognition or MCI. For each individual in the study, we first determined the observation time contributed to a given age and gender group. We then summed individual observation times for a given age and gender group over all cohort members so as to obtain the total number of person-years of observation in that category. The total number of participants with a particular transition was estimated by summing predicted probabilities of the particular transition from the weighted multinomial models over all participants in the age and gender combination group. Since not all participants received clinical evaluation at the second stage, weighted multinomial models combining data from all evaluation waves and accounting for sampling selection were used to provide estimated probabilities of participants diagnosed as normal cognition or MCI at each evaluation wave. Both the estimated cases of transition and the person-years at risk were further adjusted by these estimated probabilities for those not clinically evaluated in a previous wave.

The transition rates for a specific age and gender group were derived as the total estimated number of a particular transition divided by the total person-years at risk for the age and 
gender group. Since the transition rates were derived from complex models, we chose to use a nonparametric method, the jackknife variance estimator, for the derivation of standard errors of the rates. The jackknife variance estimator has been shown to be a consistent variance estimator for data from complex sampling ${ }^{38}$ and is more stable than the bootstrap estimator. ${ }^{39}$

Age-standardized overall transition rates were obtained by applying the estimated age and gender specific rates to the age and gender distribution of African American residents in Marion County (Indianapolis) observed in the 2000 census. The variance of the overall agestandardized rate was calculated as a weighted mean of the variances of the age and gender specific rates. Ninety-five percent confidence intervals for the transition rates were constructed based on asymptotic normality of the estimates.

\section{Results}

In the baseline evaluation of the 1992 cohort, 65 participants were diagnosed with dementia leaving 2147 participants free of dementia and eligible for continued follow-up evaluation. In the baseline evaluation of the 2001 cohort, 57 participants were diagnosed with dementia leaving 1835 participants eligible for continued follow-up evaluation. Thus a total of 3982 subjects were included in this analysis. The maximum follow-up time was 17.6 years for participants in the 1992 cohort and 8.5 years for those in the 2001 cohort. Mean follow-up time was 5.9 years $(\mathrm{SD}=5.2)$ for participants in the 1992 cohort and 4.4 years $(\mathrm{SD}=3.1)$ for the 2001 cohort. Figure 1 provides a schematic flow of the longitudinal study and information on loss to follow-up due to death, refusal and other reasons at each evaluation.

In Table 1, we present the baseline characteristics of study participants divided into three groups: those diagnosed with incident dementia during follow-up, those diagnosed with MCI at any time during the study, and those free of dementia or MCI during follow-up. In both cohorts, age, years of education, history of smoking and baseline CSID scores were significantly different among the three groups. In addition, the 2001 cohort also showed significant difference in the proportions of female, cancer, stroke and depression among the three groups while no significant differences on these proportions were seen in the 1992 cohort.

We present clinical outcomes during two consecutive evaluations in Table 2. Few individuals transitioned from normal cognition to dementia between two consecutive evaluations, but a substantial number of normal participants and those without clinical assessments were diagnosed as MCI at the subsequent evaluation. Table 3 presents age and gender specific annual transition rates from normal cognition to MCI, dementia or AD. For both men and women, the transition rates from normal cognition to MCI, dementia or AD increase with age. For participants in age groups 75-79 and 80-84, male participants had significantly higher MCI incidence rates, i.e. transition rates from normal cognition to MCI, than females based on the non-overlapping confidence intervals, while no significant gender difference was found for the other age groups. For older participants (age 280 ), female participants had significantly higher annual transition rates from normal cognition to dementia than males. The overall standardized annual incidence for MCI is 5.6\% (95\% CI: 
4.6-6.6\%), and the overall standardized annual transition rate from normal cognition to dementia is $0.6 \%$ (95\% CI: $0.6-0.7 \%$ ).

Table 4 presents age and gender specific annual transition rates from MCI to normal cognition, dementia or AD. For the reversion rates from MCI to normal, a decreasing trend with age was seen where older participants were less likely to revert back to normal than younger participants. Progression rates from MCI to dementia or AD, on the other hand, increased with the increase of age. No gender difference was seen for any of the transitions from MCI. The overall standardized annual reversion rate from MCI to normal cognition is $18.6 \%$ (95\% CI: $16.7-20.4 \%$ ). The overall standardized annual progression rate from MCI to dementia is $5.9 \%$ (95\% CI: 5.3-6.5\%). Figure 1 is a graphical display of these transitional rates.

\section{Discussion}

Previous studies on MCI incidence have used the traditional closed cohort approach by following only individuals with normal cognition at baseline to observe new MCI cases. Similarly, studies on MCI to dementia conversion were conducted by following only the group of MCI individuals at baseline and observing their progression to dementia. Given the transient nature of the MCI group, a closed cohort approach would not be able to appropriately adjust for transitions between normal cognition and MCI during the follow-up period. Our study uses a dynamic cohort approach to simultaneously estimate the transition probabilities among normal cognition, $\mathrm{MCI}$ and dementia, thus allowing the modeling of dynamic changes in cognitive status of all individuals in the cohort.

Among community-based and clinic based studies reporting incidence of MCI, annual incidence rates of MCI varied greatly from $0.85 \%$ to $12.2 \% .^{3-5,7-19}$ In Figure 3, we present annual incidence rates of MCI reported in previous studies and our results. The discrepancy in MCI incidence rates was largely attributed to differences in MCI definitions which includes cognitive impairment no dementia (CIND), age-associated memory impairment (AAMI), mild cognitive impairment (MCI), and amnestic MCI (aMCI) with aMCI being the most restrictive. Difference in rates may also reflect differences in age ranges, sample sizes, study populations, lengths of follow-up, and geographic regions. Among studies using similar diagnostic criteria to ours, there is a closer agreement in incidence rate estimates. Plassman et al reported annual CIND incidence of $6.04 \% 40$ with an eight-year follow-up and the Canadian Study of Health and Aging reported annual incidence rates of $4.58 \%$ and $5.68 \%$, respectively, for two populations followed for five years, ${ }^{18-19}$ all in close agreement with our overall annual incidence rate of $5.6 \%$.

Progression rates from MCI to dementia have been reported much higher progression rates in clinic-based cohorts than in community-based cohorts. ${ }^{20,41}$ In community-based studies, annual progression rates from $\mathrm{MCI}$ to dementia ranged from as low as $0.9 \%{ }^{42}$ to as high as $15.3 \% .{ }^{43}$ It should be noted that the meta-analysis of twelve community-based MCI studies reported a pooled annual progression rate from MCI to dementia to be $5.2 \%$ (95\% CI: 2.9$8.0 \%$ ), which is very similar to the $5.9 \%$ annual progression rate found in this study, despite of the wide variability in MCI dementia progression rates seen in these studies. ${ }^{20}$ 
Several epidemiological studies have reported that $16 \%$ to $50 \%$ of individuals with MCI reverted to normal cognition during various length of follow-up ranging from 3 to 10 years. ${ }^{2-5,7}$ Since some studies did not provide annual rates, it is difficult to directly compare our MCI reversion rates to these previous rates. Our analysis provides the longest follow-up in studies reporting MCI reversion rates. In our cohort, about $18.6 \%$ of MCI individuals reverted to normal cognition annually. However, the reversion rates decrease greatly with the increase in age, and in the older age groups more $\mathrm{MCI}$ individuals progress to dementia or $\mathrm{AD}$ than reverting to normal cognition.

Our results indicate a much higher transition rate to dementia from individuals with MCI than those with normal cognition, providing support to the notion that $\mathrm{MCI}$ as a group is at greater risk for dementia and should perhaps be targeted for early intervention to delay their transition into dementia. However, our results also highlight a cautionary note that a substantial proportion of individuals in the MCI group, especially those in the younger age groups, are more likely to revert back to normal cognition. Further research identifying predictive factors for progression or reversion in MCI individuals is needed to better define sub-groups within MCI so that intervention could be delivered to those at the early stage of dementia and unnecessary treatment could be avoided in those who would revert to normal cognition.

Most previous studies either included only Caucasian participants or did not separately report rate estimates by racial groups. We found no MCI incidence, progression or reversion rates for African Americans in the literature other than a report of incidence estimates from our study with a shorter follow-up. ${ }^{7}$ In spite of the higher prevalence rates of $\mathrm{AD}$ and dementia in African Americans reported in some studies, ${ }^{21}$ our previous publications reported $\mathrm{AD}$ and dementia incidence rates comparable to those found in Caucasian populations. ${ }^{26}$ Our results are similar to those reported from large community-based studies of Caucasians suggesting little or no difference in MCI incidence or progression rates between African Americans and Caucasians. This conclusion however will need to be verified by studies with sufficiently large samples of both African Americans and Caucasian participants to rule out potential biases due to differences among studies.

Our study has the strength of a long follow-up period in a large dynamic cohort of elderly African Americans. Identical diagnostic criteria were used throughout the entire study period, ensuring diagnostic consistency. In addition, random sampling was used for the selection of clinical assessment, thus permitting the use of weighted models to appropriately adjust for the sampling schemes and for the use of predicted probability of transitions. ${ }^{44}$

Our study also has limitations. The study included only African American participants, thus it is not known whether the rates reported here are generalizable to other elderly populations. We present transition rate estimates for all MCI individuals instead of by various MCI subtypes in order to preserve sufficient sample size for the modeling approach used in this analysis. Since not all study participants received the extensive clinical assessment at the second stage, our estimated transition rates may not be as accurate as if every participant had received the extensive clinical assessment. Nevertheless, the two stage sampling design and our model-based approach have been used in many epidemiologic studies to estimate both 
prevalence and incidence rates ${ }^{25-26,45}$ and have been shown to provide unbiased and accurate estimates under various assumptions. ${ }^{44}$

Our rate estimates could also be affected by selection biases from participants' refusal to enroll in the study, in particular, the relatively high refusal rate in the 2001 cohort. Despite differences in enrollment strategies, our previous analyses found no differences in prevalence rates of dementia or AD between the 1992 cohort and the 2001 cohort. $^{24}$ Our decision to estimate transition rates using the combined cohorts provides large sample size for stable rate estimates for age and gender subgroups. But selection bias based upon the differential refusal rates cannot be entirely ruled out. Another source of potential selection bias comes from refusals to the second stage clinical assessment. Although our smoothed estimates provides unbiased rate estimates if refused participants differed in age, gender, education or performance groups from those evaluated, potential bias may be introduced if the two groups differed on other characteristics not controlled in the logistic models.

In summary, in this elderly African American population we found that MCI individuals convert to dementia at a higher rate than individual with normal cognition. A substantial number of $\mathrm{MCI}$ individuals in the younger age groups revert to normal cognition during follow-up. Both MCI incidence rates and MCI to dementia progression rates increase with age, while reversion rates from MCI to normal decrease with age. Future research is needed to identify factors related to MCI progression and reversion.

\section{Acknowledgments}

The research is supported by NIH grants R01 AG09956, R01 AG019181, and P30 AG10133.

\section{References}

1. Petersen RC, Smith GE, Waring SC, Ivnik RJ, Tangalos EG, Kokmen E. Mild cognitive impairment: clinical characterization and outcome. Arch Neurol. 1999 Mar; 56(3):303-8. [PubMed: 10190820]

2. Ritchie K, Artero S, Touchon J. Classification criteria for mild cognitive impairment: a populationbased validation study. Neurology. 2001 Jan 9; 56(1):37-42. [PubMed: 11148233]

3. Larrieu S, Letenneur L, Orgogozo JM, Fabrigoule C, Amieva H, Le Carret N, et al. Incidence and outcome of mild cognitive impairment in a population-based prospective cohort. Neurology. 2002 Nov 26; 59(10):1594-9. [PubMed: 12451203]

4. Solfrizzi V, Panza F, Colacicco AM, D'Introno A, Capurso C, Torres F, et al. Vascular risk factors, incidence of MCI, and rates of progression to dementia. Neurology. 2004 Nov 23; 63(10):1882-91. [PubMed: 15557506]

5. Ganguli M, Dodge HH, Shen C, DeKosky ST. Mild cognitive impairment, amnestic type: an epidemiologic study. Neurology. 2004 Jul 13; 63(1):115-21. [PubMed: 15249620]

6. Hanninen T, Hallikainen M, Koivisto K, Helkala EL, Reinikainen KJ, Soininen H, et al. A followup study of age-associated memory impairment: neuropsychological predictors of dementia. J Am Geriatr Soc. 1995 Sep; 43(9):1007-15. [PubMed: 7657916]

7. Unverzagt FW, Ogunniyi A, Taler V, Gao S, Lane KA, Baiyewu O, et al. Incidence and risk factors for cognitive impairment no dementia and mild cognitive impairment in African Americans. Alzheimer Dis Assoc Disord. 2011 Jan-Mar;25(1):4-10. [PubMed: 20921881]

8. Busse A, Bischkopf J, Riedel-Heller SG, Angermeyer MC. Mild cognitive impairment: prevalence and incidence according to different diagnostic criteria. Results of the Leipzig Longitudinal Study of the Aged (LEILA75+). Br J Psychiatry. 2003 May.182:449-54. [PubMed: 12724250] 
9. Chaves ML, Camozzato AL, Godinho C, Piazenski I, Kaye J. Incidence of mild cognitive impairment and Alzheimer disease in Southern Brazil. J Geriatr Psychiatry Neurol. 2009 Sep; 22(3): 181-7. [PubMed: 19307320]

10. Luck T, Luppa M, Briel S, Matschinger H, Konig HH, Bleich S, et al. Mild cognitive impairment: incidence and risk factors: results of the leipzig longitudinal study of the aged. J Am Geriatr Soc. 2010 Oct; 58(10):1903-10. [PubMed: 20840461]

11. Manly JJ, Tang MX, Schupf N, Stern Y, Vonsattel JP, Mayeux R. Frequency and course of mild cognitive impairment in a multiethnic community. Ann Neurol. 2008 Apr; 63(4):494-506. [PubMed: 18300306]

12. Ravaglia G, Forti P, Montesi F, Lucicesare A, Pisacane N, Rietti E, et al. Mild cognitive impairment: epidemiology and dementia risk in an elderly Italian population. J Am Geriatr Soc. 2008 Jan; 56(1):51-8. [PubMed: 18028343]

13. Tervo S, Kivipelto M, Hanninen T, Vanhanen M, Hallikainen M, Mannermaa A, et al. Incidence and risk factors for mild cognitive impairment: a population-based three-year follow-up study of cognitively healthy elderly subjects. Dement Geriatr Cogn Disord. 2004; 17(3):196-203. [PubMed: 14739544]

14. Verghese J, LeValley A, Derby C, Kuslansky G, Katz M, Hall C, et al. Leisure activities and the risk of amnestic mild cognitive impairment in the elderly. Neurology. 2006 Mar 28; 66(6):821-7. [PubMed: 16467493]

15. Caracciolo B, Palmer K, Monastero R, Winblad B, Backman L, Fratiglioni L. Occurrence of cognitive impairment and dementia in the community: a 9-year-long prospective study. Neurology. 2008 May 6; 70(19 Pt 2):1778-85. [PubMed: 18184916]

16. Wilson RS, Schneider JA, Arnold SE, Tang Y, Boyle PA, Bennett DA. Olfactory identification and incidence of mild cognitive impairment in older age. Arch Gen Psychiatry. 2007 Jul; 64(7):802-8. [PubMed: 17606814]

17. Baiyewu O, Unverzagt FW, Ogunniyi A, Hall KS, Gureje O, Gao S, et al. Cognitive impairment in community-dwelling older Nigerians: clinical correlates and stability of diagnosis. Eur J Neurol. 2002 Nov; 9(6):573-80. [PubMed: 12453071]

18. Hsiung GY, Sadovnick AD, Feldman H. Apolipoprotein E epsilon4 genotype as a risk factor for cognitive decline and dementia: data from the Canadian Study of Health and Aging. CMAJ. 2004 Oct 12; 171(8):863-7. [PubMed: 15477624]

19. Tuokko H, Frerichs R, Graham J, Rockwood K, Kristjansson B, Fisk J, et al. Five-year follow-up of cognitive impairment with no dementia. Arch Neurol. 2003 Apr; 60(4):577-82. [PubMed: 12707072]

20. Mitchell AJ, Shiri-Feshki M. Rate of progression of mild cognitive impairment to dementia--metaanalysis of 41 robust inception cohort studies. Acta Psychiatr Scand. 2009 Apr; 119(4):252-65. [PubMed: 19236314]

21. 2010 Alzheimer's disease facts and figures. Alzheimers Dement. 2010 Mar; 6(2):158-94. [PubMed: 20298981]

22. Chobanian AV, Bakris GL, Black HR, Cushman WC, Green LA, Izzo JL, et al. The Seventh Report of the Joint National Committee on Prevention, Detection, Evaluation, and Treatment of High Blood Pressure - The JNC 7 Report. Jama-J Am Med Assoc. 2003 May 21; 289(19):256072.

23. Flegal KM, Carroll MD, Kit BK, Ogden CL. Prevalence of Obesity and Trends in the Distribution of Body Mass Index Among US Adults, 1999-2010. Jama-J Am Med Assoc. 2012 Feb 1; 307(5): 491-7.

24. Hall KS, Gao S, Baiyewu O, Lane KA, Gureje O, Shen J, et al. Prevalence rates for dementia and Alzheimer's disease in African Americans: 1992 versus 2001. Alzheimers Dement. 2009 May; 5(3):227-33. [PubMed: 19426950]

25. Hendrie HC, Osuntokun BO, Hall KS, Ogunniyi AO, Hui SL, Unverzagt FW, et al. Prevalence of Alzheimer's disease and dementia in two communities: Nigerian Africans and African Americans. Am J Psychiatry. 1995 Oct; 152(10):1485-92. [PubMed: 7573588]

26. Hendrie HC, Ogunniyi A, Hall KS, Baiyewu O, Unverzagt FW, Gureje O, et al. Incidence of dementia and Alzheimer disease in 2 communities: Yoruba residing in Ibadan, Nigeria, and 
African Americans residing in Indianapolis, Indiana. JAMA. 2001 Feb 14; 285(6):739-47. [PubMed: 11176911]

27. Hall KS, Ogunniyi AO, Hendrie HC, Osuntokun BO, Hui SL, Musick BS, et al. A cross-cultural community based study of dementias: methods and performance of the survey instrument: Indianapolis, U.S.A. and Ibadan, Nigeria. Int J Methods Psychiatr Res. 1996; 6:129-42.

28. Hall KS, Gao S, Emsley CL, Ogunniyi AO, Morgan O, Hendrie HC. Community screening interview for dementia (CSI 'D'); performance in five disparate study sites. Int J Geriatr Psychiatry. 2000 Jun; 15(6):521-31. [PubMed: 10861918]

29. Morris JC, Heyman A, Mohs RC, Hughes JP, van Belle G, Fillenbaum G, et al. The Consortium to Establish a Registry for Alzheimer's Disease (CERAD). Part I. Clinical and neuropsychological assessment of Alzheimer's disease. Neurology. 1989 Sep; 39(9):1159-65. [PubMed: 2771064]

30. Hendrie HC, Lane KA, Ogunniyi A, Baiyewu O, Gureje O, Evans R, et al. The development of a semi-structured home interview (CHIF) to directly assess function in cognitively impaired elderly people in two cultures. International psychogeriatrics / IPA. 2006 Dec; 18(4):653-66. [PubMed: 16640794]

31. Hendrie HC, Hall KS, Brittain HM, Austrom MG, Farlow M, Parker J, et al. The CAMDEX: a standardized instrument for the diagnosis of mental disorder in the elderly: a replication with a US sample. J Am Geriatr Soc. 1988 May; 36(5):402-8. [PubMed: 3361042]

32. Roth M, Tym E, Mountjoy CQ, Huppert FA, Hendrie H, Verma S, et al. CAMDEX. A standardised instrument for the diagnosis of mental disorder in the elderly with special reference to the early detection of dementia. Br J Psychiatry. 1986 Dec.149:698-709. [PubMed: 3790869]

33. American Psychiatric Association. Diagnostic and Statistical Manual of Mental Disorders. 3. Washington, DC: American Psychiatric Assocation; 1987. Rev

34. American Psychiatric Association Press. Report No.: V.3. 1992. ICD-10. The International Statistical Classification of Diseases and Related Health Problems: 1 and 2.

35. McKhann G, Drachman D, Folstein M, Katzman R, Price D, Stadlan EM. Clinical diagnosis of Alzheimer's disease: report of the NINCDS-ADRDA Work Group under the auspices of Department of Health and Human Services Task Force on Alzheimer's Disease. Neurology. 1984 Jul; 34(7):939-44. [PubMed: 6610841]

36. Unverzagt FW, Gao S, Baiyewu O, Ogunniyi AO, Gureje O, Perkins A, et al. Prevalence of cognitive impairment: data from the Indianapolis Study of Health and Aging. Neurology. 2001 Nov 13; 57(9):1655-62. [PubMed: 11706107]

37. Graham JE, Rockwood K, Beattie BL, Eastwood R, Gauthier S, Tuokko H, et al. Prevalence and severity of cognitive impairment with and without dementia in an elderly population. Lancet. 1997 Jun 21; 349(9068):1793-6. [PubMed: 9269213]

38. Krewski D, Rao JNK. Inference from stratified samples: properties of the linearization, jack-knife and balanced repeated replication methods. Annals of Statisics. 1981; 9:1010-9.

39. Rao JNK, Wu CJ. Resampling inference with complex survey data. Journal of the American Statistical Association. 1988; 83:231-41.

40. Plassman BL, Langa KM, McCammon RJ, Fisher GG, Potter GG, Burke JR, et al. Incidence of dementia and cognitive impairment, not dementia in the United States. Ann Neurol. 2011 Sep; 70(3):418-26. [PubMed: 21425187]

41. Farias ST, Mungas D, Reed BR, Harvey D, DeCarli C. Progression of mild cognitive impairment to dementia in clinic- vs community-based cohorts. Arch Neurol. 2009 Sep; 66(9):1151-7. [PubMed: 19752306]

42. Tyas SL, Salazar JC, Snowdon DA, Desrosiers MF, Riley KP, Mendiondo MS, et al. Transitions to mild cognitive impairments, dementia, and death: findings from the Nun Study. Am J Epidemiol. 2007 Jun 1; 165(11):1231-8. [PubMed: 17431012]

43. Tschanz JT, Welsh-Bohmer KA, Lyketsos CG, Corcoran C, Green RC, Hayden K, et al. Conversion to dementia from mild cognitive disorder: the Cache County Study. Neurology. 2006 Jul 25; 67(2):229-34. [PubMed: 16864813]

44. Beckett LA, Scherr PA, Evans DA. Population prevalence estimates from complex samples. J Clin Epidemiol. 1992 Apr; 45(4):393-402. [PubMed: 1569435] 
45. Evans DA, Funkenstein HH, Albert MS, Scherr PA, Cook NR, Chown MJ, et al. Prevalence of Alzheimer's disease in a community population of older persons. Higher than previously reported. JAMA. 1989 Nov 10; 262(18):2551-6. [PubMed: 2810583] 


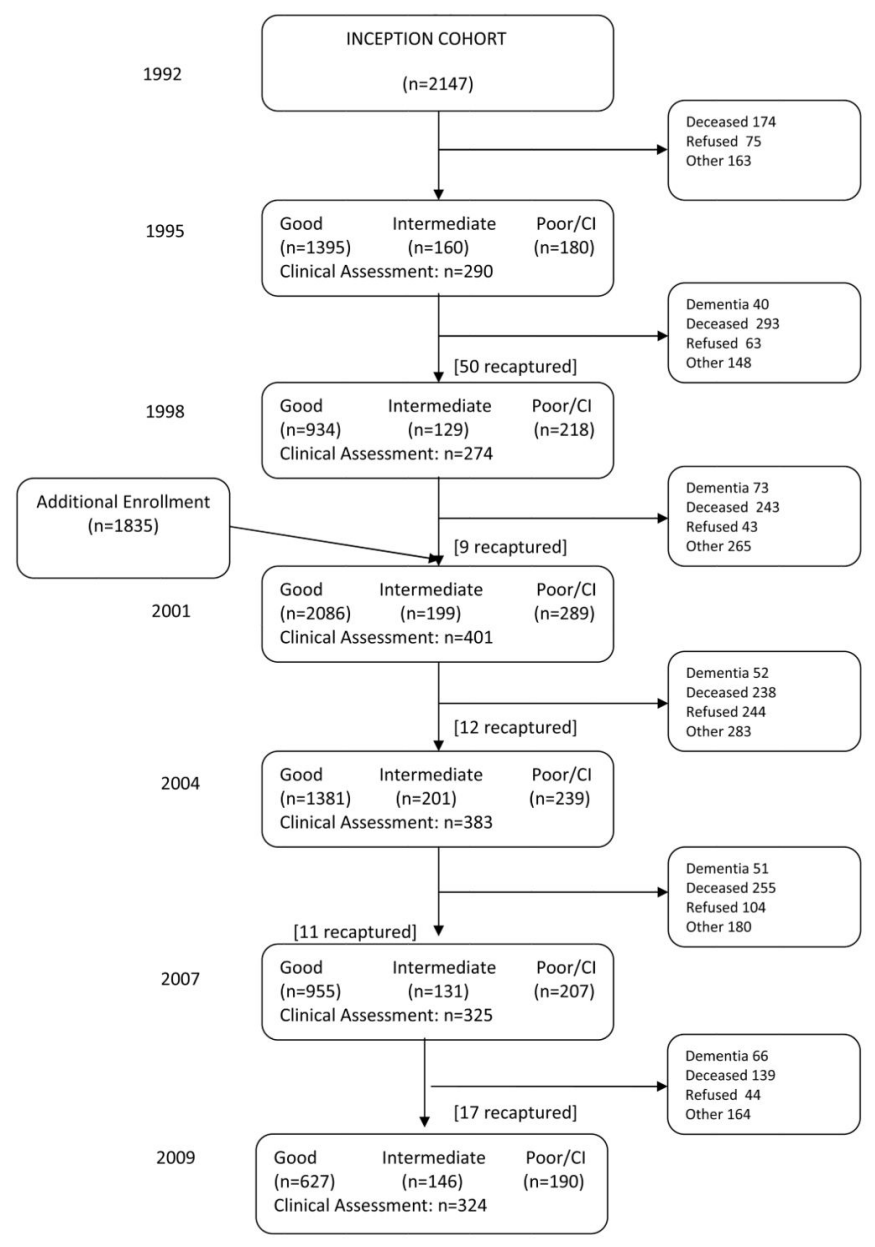

Figure 1.

Flow chart of the number of study participants evaluated during follow-up. 

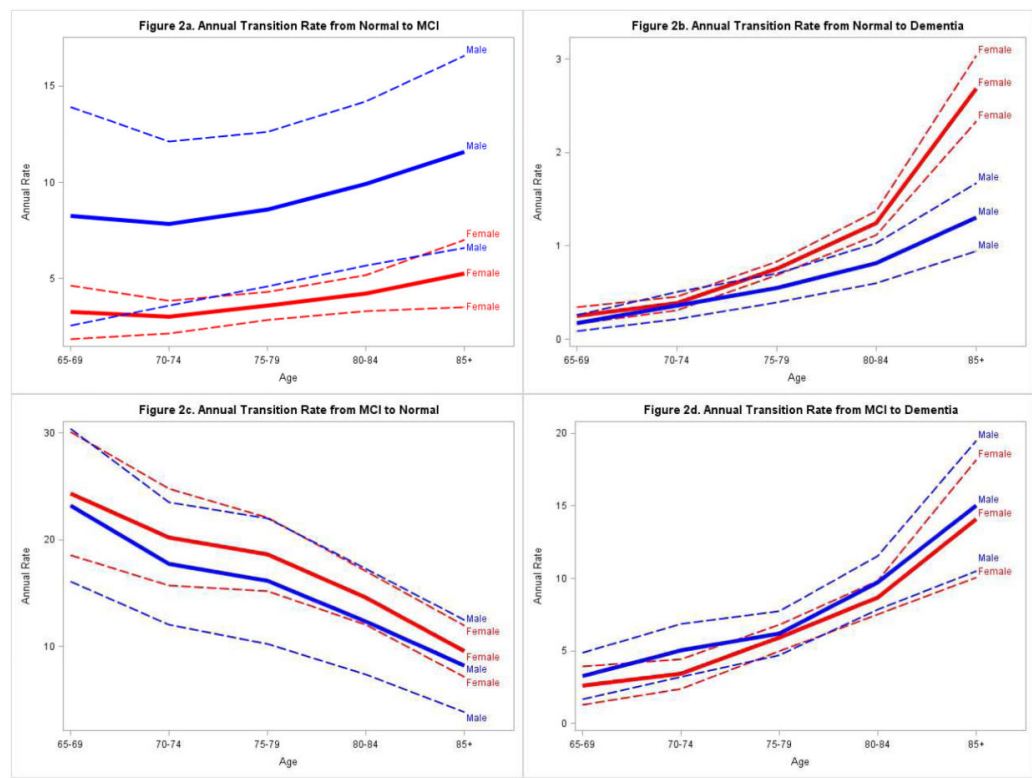

Figure 2.

Age and gender specific annual transition rates and 95\% confidence intervals. Red lines represent estimated rates (solid lines) and confidence intervals (dotted lines) in females. Blue lines represent estimated rates (solid lines) and confidence intervals (dotted lines) in males. 


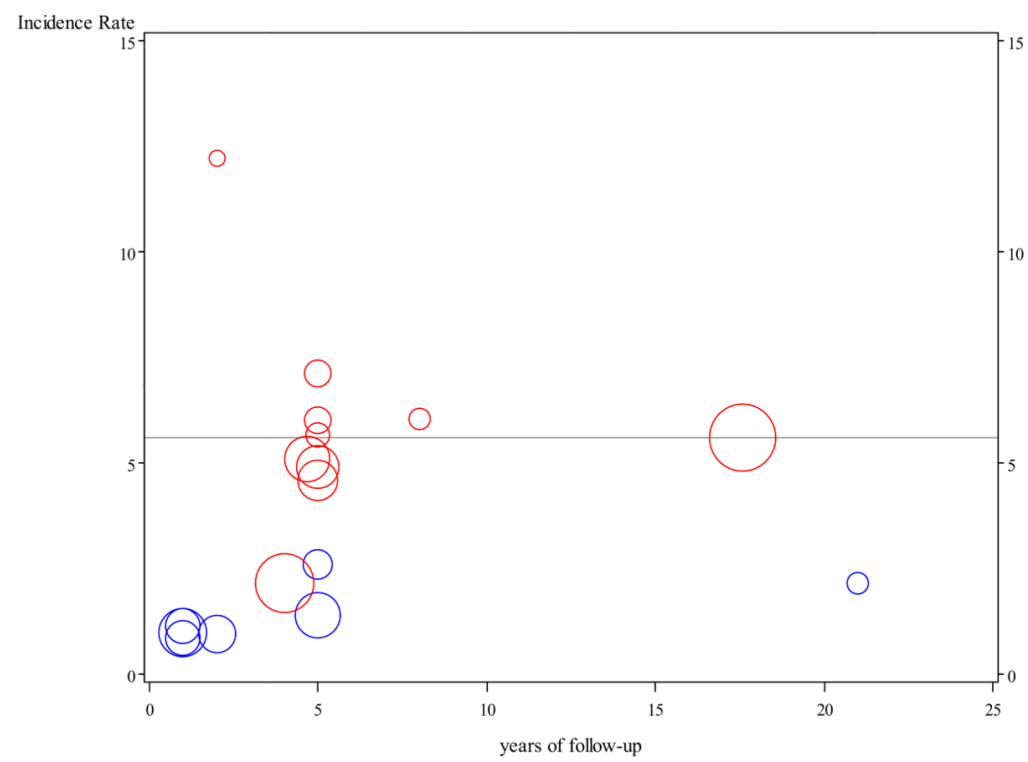

Figure 3.

Incidence rates for mild cognitive impairment (MCI) reported in the literature and in this study (horizontal line). Blue dots represent incidence rates for amnestic MCI and red dots represent rates for all types of MCI. The sizes of the dots are proportional to study sample sizes. 


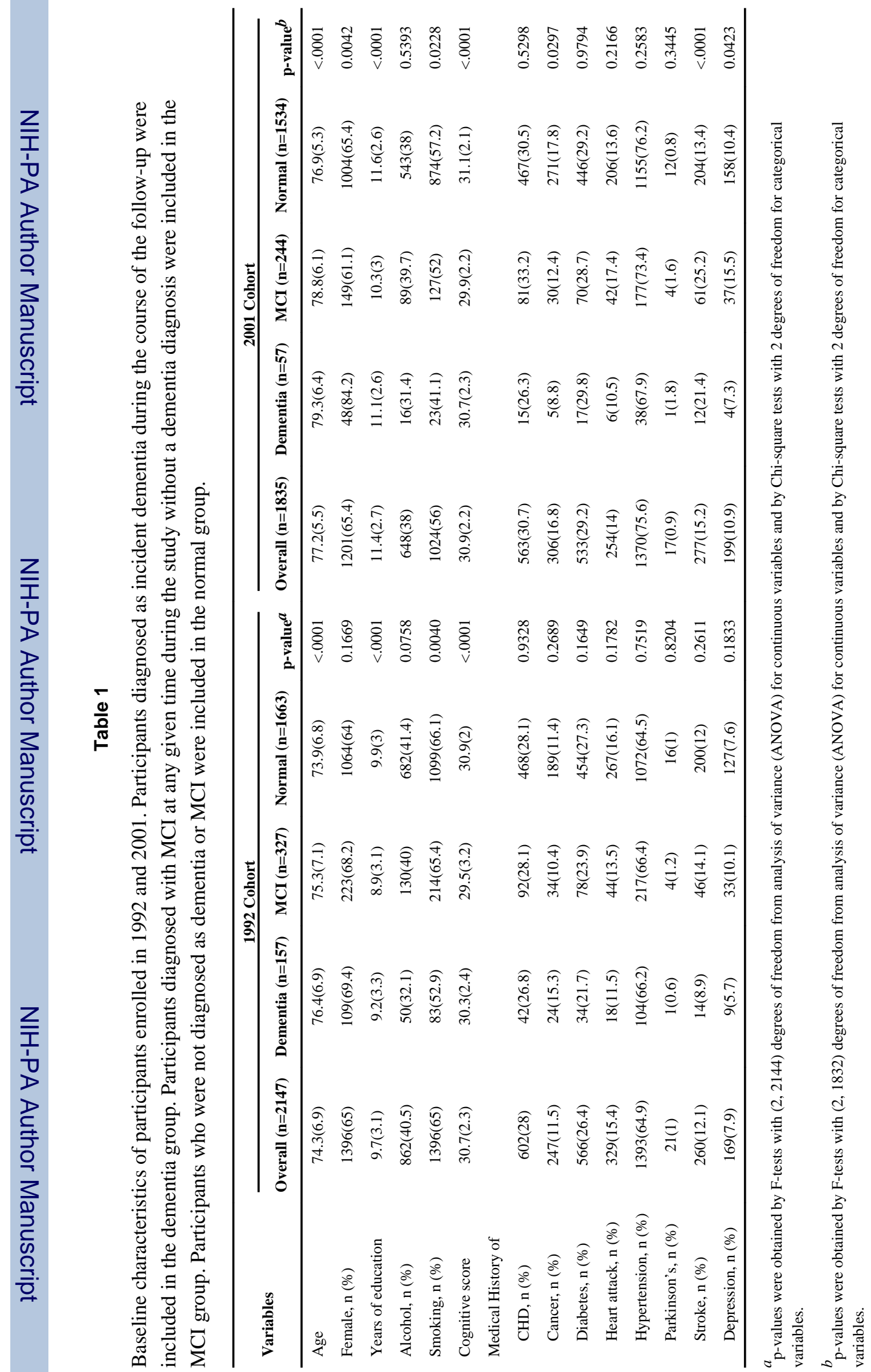
Am J Geriatr Psychiatry. Author manuscript; available in PMC 2015 July 01. 


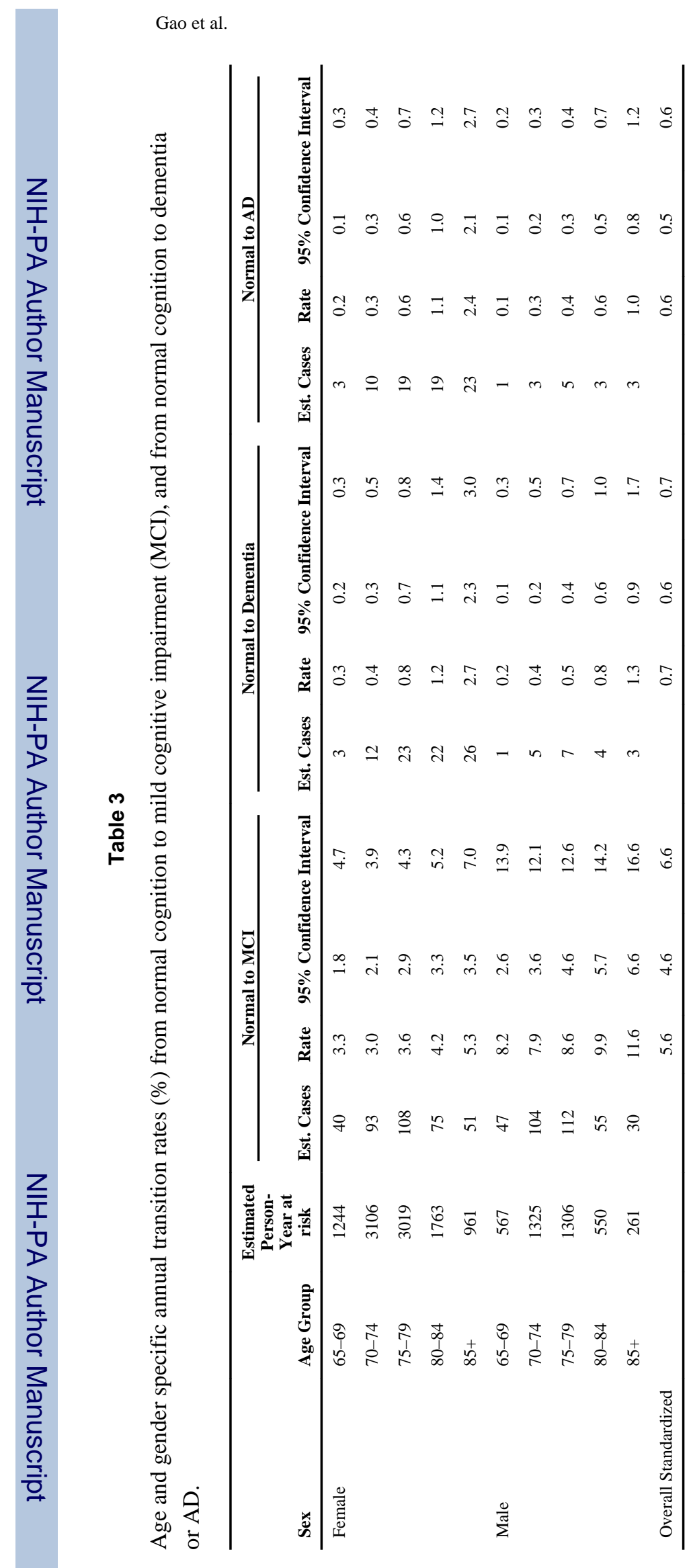

Page 18 


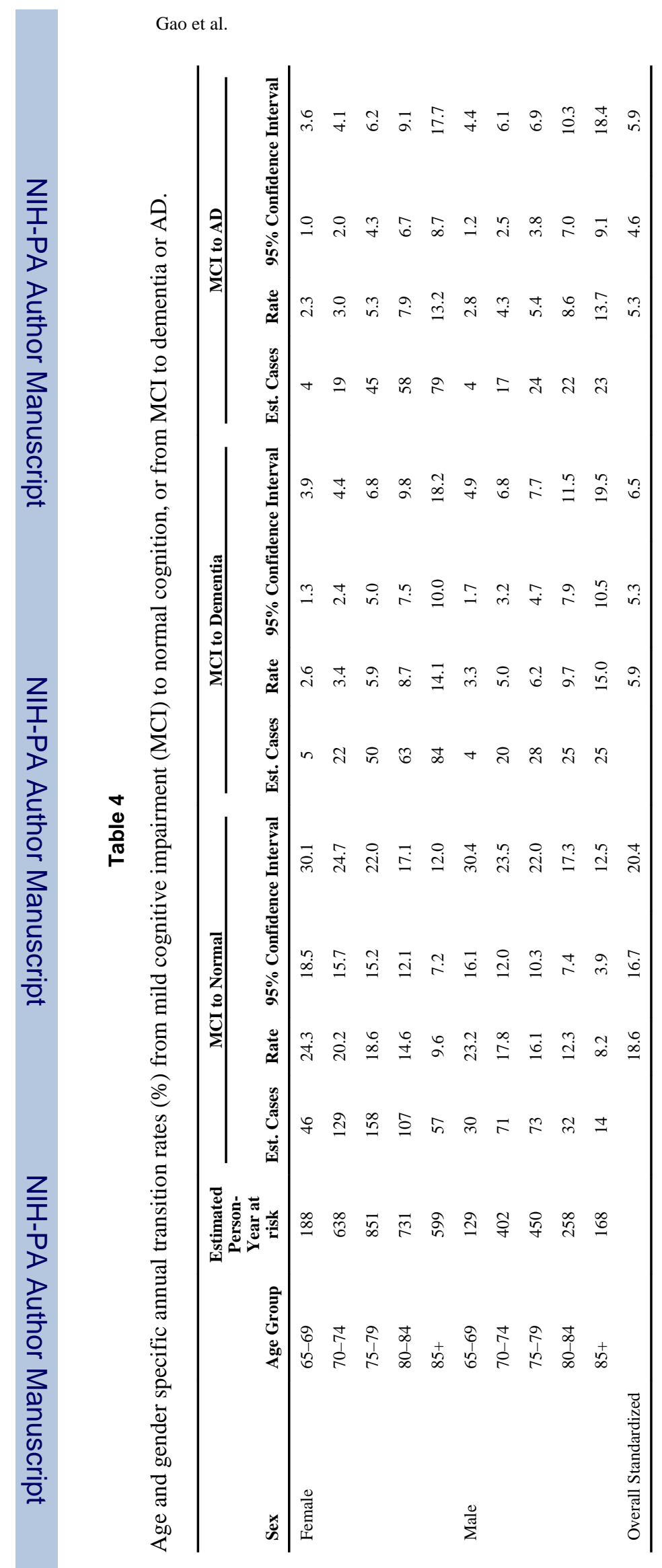

Page 19 